ORIGINAL ARTICLE

\title{
The role of magnetic resonance imaging in the assessment of suspected extrinsic tracheobronchial compression due to vascular anomalies
}

\author{
T H Malik, I A Bruce, V Kaushik, D J Willatt, N B Wright, M P Rothera
}

Figures 1,2 , and $5-8$ are available on the $A D C$ website (www. archdischild.com/ supplemental)

See end of article for authors' affiliations

Correspondence to: Mr T Malik, 37 Glenside Drive, Wilmslow, Cheshire SK9 1EH, UK; Tasshm@ aol.com

Accepted 25 April 2005 Published Online First 4 May 2005

Arch Dis Child 2006;91:52-55. doi: 10.1136/adc.2004.070250

Aims: To evaluate the role of magnetic resonance imaging (MRI) in the assessment of children with suspected extrinsic tracheobronchial compression due to vascular anomalies.

Methods: Retrospective case note review in a tertiary referral centre. Twenty nine children who underwent dynamic laryngotracheobronchoscopy (DLTB) and were found to have a clinical suspicion of extrinsic tracheobronchial compression were evaluated. All subsequently underwent thoracic MRI within 10 days. The findings on endoscopy were compared to those of MRI, and where performed, echocardiography, aortography, and surgery.

Results: There were 17 males and 12 females (mean age 5 months, range 28 weeks gestation to 60 months). The most common presenting features were stridor and cyanotic episodes. MRI showed abnormalities in 21 patients. There were five vascular rings (three double aortic arches and two right aortic arches) and 11 cases of innominate artery compression. Other vascular anomalies noted included aberrant right subclavian artery and aneurysmal left pulmonary artery. Echocardiography was generally found to be unhelpful in the diagnosis of extra-cardiac vascular abnormalities. Angiography was subsequently conducted in eight children; findings agreed with those shown on MRI. Surgery was performed on all five vascular rings, one innominate artery compression, and one aneurysmal left pulmonary artery. Surgical findings were also compatible with the preoperative MRI.

Conclusions: This study shows the successful use of MRI as the initial imaging modality in endoscopically suspected extrinsic vascular compression of the upper airway. It enables accurate delineation of vascular anomalies and, unlike aortography, is non-invasive and does not require the use of contrast media.

$\mathrm{T}$ horacic vascular anomalies are potentially life threatening but treatable causes of tracheobronchial obstruction in infancy. The resultant airway compromise occurs as a direct consequence of physical external compression of the airway lumen, but may also reflect the subsequent development of secondary tracheobronchomalacia. ${ }^{.}$When symptomatic, these patients may present with stridor (commonly misdiagnosed as asthma), croup-like cough, recurrent lower respiratory tract infections, dysphagia, and episodic apnoea. As a consequence of the airway obstruction, the patient's ability to clear secretions from the airways distal to the level of compression may be compromised. The resulting accumulation of secretions increases both the risk of secondary infection and accompanying inflammation, which may result in airway irritation and a croup-like cough. ${ }^{2}$

Thoracic magnetic resonance imaging (MRI) is becoming increasingly popular as the first line imaging modality in the diagnostic workup of paediatric airway obstruction suspected to be due to vascular anomalies of the aortic arch system and its major branches. ${ }^{2-5}$ Advocates of MRI maintain that it is both non-invasive and can accurately differentiate the various forms of vascular tracheobronchial compression from other causes of respiratory obstruction such as foreign bodies, haemangiomas, bronchogenic cysts, and mediastinal tumours. ${ }^{2}$ It also avoids the use of ionising radiation.

This study describes our experience of children seen at The Royal Manchester Children's University Hospital over a two year period, who were found to have a clinical suspicion of vascular airway compression at dynamic laryngotracheobronchoscopy (DLTB) and subsequently underwent MRI.

\section{METHODS}

A database review at our paediatric tertiary referral centre was undertaken. Cases were identified where there had been a clinical suspicion of extrinsic tracheobronchial vascular compression recorded at DLTB. Typically this suspicion would involve a pulsatile indentation or constriction of the tracheobronchial wall with reduction of the cross-sectional area at characteristic sites and configurations described later. The DLTB was performed using a rigid laryngoscope through which a $2.7 \mathrm{~mm} 0^{\circ}$ rigid endoscope (Hopkin's rod) was introduced. By performing a dynamic procedure any malacic segments would also become apparent. The level of anaesthesia was such that it prevented coughing but allowed for spontaneous ventilation using nasopharyngeal intubation, with the end of the tube situated in the hypopharynx. The vocal folds were sprayed with local anaesthetic spray.

These children then routinely underwent thoracic MRI (T1 weighted, echo planar imaging in three orthagonal planes (spin-echo with EPI) and additional turbo field echo transverse images to provide angiographic information) within 10 days of the DLTB. Sedation was given during MRI by means of oral chloral hydrate $100 \mathrm{mg} / \mathrm{kg}$ (maximum $2.0 \mathrm{~g}$ ) with or without rectal paraldehyde $0.3 \mathrm{ml} / \mathrm{kg}$ for children weighing $\leqslant 20 \mathrm{~kg}$, and oral quinalbarbitone (secobarbital) $10 \mathrm{mg} / \mathrm{kg}$ (maximum $200 \mathrm{mg}$ ) for those weighing $>20 \mathrm{~kg}$.

Abbreviations: DLTB, dynamic laryngotracheobronchoscopy; MRI, magnetic resonance imaging 
A case note review was conducted and the findings on endoscopy were then compared to those of MRI, and where performed, echocardiography, aortography, and surgery.

\section{RESULTS}

We identified 29 cases where children had a clinical suspicion of external vascular compression on DLTB. All subsequently underwent thoracic MRI as is the policy at out unit. There were 17 males and 12 females, with a mean age of 5 months (range 28 weeks gestation to 60 months). The presenting features are summarised in table 1.

Of the 29 patients, MRI was normal in eight children $(27.5 \%)$. None of the patients with normal magnetic resonance scans were later diagnosed as having vascular compression, either clinically or using other radiological modalities, during the follow up period of at least 18 months. Anomalies found on MRI are shown in table 2, and depicted in figs 1-8 (see the $A D C$ website for figs 1, 2, and 5-8: www.archdischild.com/supplemental).

Echocardiography was performed in 19 of the 29 cases. Apart from hinting at one case of a right aortic arch, and another of left pulmonary artery aneurysm, this investigation was found to be unhelpful in the diagnosis of extra-cardiac vascular anomalies. Barium swallow was performed in two of the five cases later diagnosed as vascular rings: one was correctly diagnosed as a right aortic arch, but the other failed to visualise a double aortic arch.

Eight of the twenty one patients with abnormalities identified on MRI went on to have aortography. The findings at aortography were in agreement with the MRI findings in all five vascular rings, two cases of innominate artery compression (causing $>50 \%$ tracheal compression), and the case of aneurysmal left pulmonary artery.

Surgery was performed in seven cases, comprising all five vascular rings, one innominate artery compression (causing $>50 \%$ tracheal compression), and the aneurysmal left pulmonary artery. The findings at operation were in concordance with the preoperative MRI in all cases.

\section{DISCUSSION}

Developmental anomalies of the aortic arch and its branches have two effects on the upper airway. Firstly they cause direct extrinsic compression with reduction of the luminal area, and secondly they cause malacia because the airway wall weakens and becomes more compliant and collapsible. Mucociliary clearance of secretions can also be impaired, compounding the functional airway obstruction and leading to infections and chronic cough. ${ }^{7}$

The most common presenting complaint in our series was stridor, which occurred in $69 \%$ of patients, in agreement with the literature. ${ }^{89}$ Fifteen patients presented with either episodic apnoea or cyanotic episodes. Such episodes are also referred to as reflex apnoea or "death spells". ${ }^{9}$ It has been hypothesised that such episodes of respiratory arrest result from tracheal irritation at the site of compression. ${ }^{10}$

Airway obstruction resulting from innominate artery compression (IAC) (see figs 1 and 2 on the $A D C$ website:

\begin{tabular}{lc}
\hline Table 1 Presenting symptoms \\
\hline Symptom & Number \\
\hline Stridor & $20(69 \%)$ \\
Cyanotic episodes & $9(31 \%)$ \\
Apnoeic episodes & $6(21 \%)$ \\
Choking episodes & $4(14 \%)$ \\
Recurrent chest infections & $2(7 \%)$ \\
Dysphagia/regurgitation & $0(0 \%)$ \\
\hline
\end{tabular}

Table 2 Findings on MRI

\begin{tabular}{|c|c|c|c|}
\hline Findings on MRI & $\begin{array}{l}\text { No. of } \\
\text { cases }\end{array}$ & $\%$ & Figures \\
\hline \multicolumn{4}{|l|}{ Innominate artery compression } \\
\hline$<20 \%$ tracheal compression & 6 & & 1,2 \\
\hline $20-50 \%$ tracheal compression & & 38 & \\
\hline$>50 \%$ tracheal compression & $3 \int$ & & \\
\hline \multicolumn{4}{|l|}{ Complete vascular ring } \\
\hline Double aortic arch & $3\}$ & & 3,4 \\
\hline Right aortic arch & $2\}$ & 17 & 5,6 \\
\hline Aberrant right subclavian artery & $\overline{1}$ & 3.5 & 7,8 \\
\hline Aneurysmal left pulmonary artery & 1 & 3.5 & \\
\hline Right bronchogenic cyst & 1 & 3.5 & \\
\hline Intrinsic tracheal stenosis & 1 & 3.5 & \\
\hline Primary tracheomalacia & 1 & 3.5 & \\
\hline No abnormality & 8 & 27.5 & \\
\hline
\end{tabular}

www.archdischild.com/supplemental) may result in an expiratory or biphasic wheeze, or stridor. Patients may also present with a "croupy" barking cough, reflex apnoea, and recurrent lower respiratory tract infections. ${ }^{11}$ Any compromise associated with IAC is often self-limiting and improves with increasing age. ${ }^{11}$ At DLTB a right anterior compression is seen above the carina, synchronous with the pulse. IAC has been shown to be associated with oesophageal atresia and severe gastro-oesophageal reflux disease. ${ }^{5}$ IAC with up to $90 \%$ tracheal compression can usually be treated expectantly, but severe or complicated cases require aortopexy whereby the innominate artery is secured to the posterior surface of the sternum, thus relieving the anterior tracheal compression. ${ }^{9}$ While MRI elegantly shows IAC, it does not predict the need for surgical intervention: ${ }^{4}$ in our series only one child required aortopexy.

A vascular ring refers to an anomaly of the aortic arch system and its major branches that encircles and compresses



Figure 3 MRI scan of double aortic arch. Coronal T1 images. (A) Origin of the right and left common carotid arteries from their respective arches (arrows). (B) Right and left arches shown either side of the trachea (arrows). (C) Origin of the right and left subclavian arteries from their respective arches (arrows). (D) Both arches join to form a single descending aorta just to the right of the midline (arrow). 


\section{What is already known on this topic}

- Approximately $3 \%$ of the general population have a congenital anomaly involving the aortic arch system. However, only a small proportion of these result in symptomatic vascular compression of the airway

- The evaluation of children suspected of having such a problem may include the use of chest radiography, barium oesophagography, echocardiography, CT, $M R I$, endoscopy, or angiography

the trachea and oesophagus. ${ }^{911}$ The most common symptomatic complete vascular ring is the double aortic arch (figs 3 and 4 ), followed by a right aortic arch in which the ring is completed by the ligamentum arteriosum (see figs 5 and 6 on the $A D C$ website: www.archdischild.com/supplemental). The most common incomplete ring is an aberrant right subclavian artery. ${ }^{211}$ The complete rings tend to present earlier. ${ }^{9}$

A double aortic arch (figs 3 and 4) is formed when the embryonic fourth aortic arches and dorsal aortic roots persist and remain patent on both sides. ${ }^{914}$ The resultant ring is tight and symptoms usually begin at birth. The stridor is biphasic in nature and exacerbated by feeding. Recurrent respiratory tract infections and cyanotic episodes are common. Significant dysphagia is not usually seen until solid food is introduced. ${ }^{211}$ One of the arches is usually of larger calibre, the right arch usually predominating 256811 as shown in our three cases. The findings on endoscopy are a concentric or triangular compression surrounding the trachea, main bronchi, and oesophagus. Double aortic arches are treated



Figure 4 Diagrammatic representation of double aortic arch. RAo, right aortic arch; Lao, left aortic arch; RSA, right subclavian artery; RCCA, right common carotid artery; LCCA, left common carotid artery; LSA, left subclavian artery; LA, ligamentum arteriosum; T, trachea; $O$, oesophagus; PA, pulmonary artery.

\section{What this study adds}

- Thoracic MRI can be used successfully to investigate children with endoscopically suspected vascular compression of the upper airway. It provides excellent detail without radiation or contrast exposure

by ligation and division of the smaller, less dominant arch, which in $80 \%$ of cases corresponds to the left aortic arch. ${ }^{9}$

The development of the right aortic arch (see figs 5 and 6 on the $A D C$ website: www.archdischild.com/supplemental) is similar to the double aortic arch, but the left arch regresses. Several variations exist, including right aortic arch with aberrant left subclavian artery and mirror image branching. ${ }^{3}{ }^{15}$ Unlike a double aortic arch anomaly, a right aortic arch with mirror image branching is often associated with congenital heart disease such as tetralogy of Fallot or pulmonary atresia. ${ }^{6}$

Persistence of the dorsal segment of the right aortic arch results in an aberrant origin of the right subclavian artery (see figs 7 and 8 on the $A D C$ website: www.archdischild.com/ supplemental). The latter now passes behind the trachea and oesophagus, indenting the oesophagus, to reach the right upper limb. ${ }^{216}$ This anomaly is not a true complete vascular ring and is often asymptomatic. It is the most common congenital arch anomaly occurring in $0.4-2.3 \%$ of the population. ${ }^{17}$ Significant airway compromise is unlikely, but this anomaly can be associated with dysphagia. ${ }^{2811} 16$

A pulmonary artery sling is produced as a result of an anomalous origin of the left pulmonary artery. In this anomaly the normal left pulmonary artery is absent and the resultant aberrant collateral vessel arises from the right pulmonary artery, tightly encircling the right bronchus and passing between the trachea and oesophagus. Significant airway compromise is common and therefore presentation occurs shortly after birth. ${ }^{9}$ Tracheomalacia and tracheal stenosis may also result. ${ }^{5}$

Non-surgical management has been shown to be effective in selected mildly symptomatic cases of vascular tracheobronchial compression, especially innominate artery compression. ${ }^{4}{ }^{18}$ Outcomes following surgical treatment are good, with complete resolution of symptoms in most cases. ${ }^{2} 91419$

Traditionally the gold standard investigation has been aortography with its inherent risks associated with exposure to ionising radiation and the use of contrast media, as well as the potential complications related to the puncture site. Other imaging modalities have been advocated in the investigation of suspected vascular tracheobronchial compression, such as contrast imaging of the oesophagus, echocardiography, and computed tomography (CT). ${ }^{1891620}$

A high degree of clinical suspicion remains the most important factor in the diagnosis of paediatric airway obstruction resulting from vascular compression. Our preferred diagnostic strategy for cases of airway obstruction involves the primary use of DLTB. It provides an unrivalled view of the entire airway, has the capability to diagnose a variety of causes of airway obstruction (for example, laryngomalacia, vocal cord palsy, and subglottic haemangioma), and permits a functional assessment of airway compromise. At present, technology is not advanced enough for MRI to be able to perform useful real-time "virtual endoscopy" and thus be considered a viable first line alternative.

The combination of DLTB and MRI proved to be a robust method of diagnosis in all the patients in this study. This study supports the first line use of MRI to investigate all endoscopically suspected extrinsic vascular compression of the upper 
airway. We found the T1 EPI "black blood" sequence to be the most useful sequence at our institution. If MRI confirms an anomaly which would require surgical intervention or is indeterminate, then one should proceed to angiography.

\section{Authors' affiliations}

T H Malik, I A Bruce, V Kaushik, D J Willatt, M P Rothera, Department of Otorhinolaryngology, Central Manchester and Manchester Children's University Hospitals NHS Trust, The Royal Manchester Children's Hospital, Hospital Road, Pendlebury, Salford M27 1HA, UK N B Wright, Department of Radiology, Central Manchester and Manchester Children's University Hospitals NHS Trust

Competing interests: none

\section{REFERENCES}

1 Gustafson LM, Liu JH, Link DT, et al. Spiral CT versus MRI in neonatal airway evaluation. Int J Pediatr Otorhinolaryngol 2000;52:197-201.

2 Erwin EA, Gerber ME, Cotton RT. Vascular compression of the airway: indications for and results of surgical management. Int J Pediatr Otorhinolaryngol 1997;40:155-62.

3 Zacharay CH, Myers JL, Eggli KD. Vascular ring due to right aortic arch with mirror-image branching and left ligamentum arteriosus: complete preoperative diagnosis by magnetic resonance imaging. Pediatr Cardiol 2001;22:71-3.

4 De Baets F, De Weghe V van, Smets A, et al. Magnetic resonance imaging in tracheal compression by the innominate artery. Arch Dis Child 1993;69:390-1.

5 Mahboubi S, Meyer JS, Hubbard AM, et al. Magnetic resonance imaging of airway obstruction resulting from vascular abnormalities. Int J Pediatr Otorhinolaryngol 1994;28:111-23.
6 Kersting-Sommerhoff BA, Sechtem UP, Fisher MR, et al. MR imaging of congenital anomalies of the aortic arch. Am J Roentgenol 1987;149:9-13.

7 Lierl M. Non infectious disorders of the respiratory tract. In: Hilman BC, ed. Pediatric respiratory disease: diagnosis and treatment. Philadelphia, PA: WB Saunders, 1993:457-97.

8 Woods RK, Sharp RJ, Holcomb GW, et al. Vascular anomalies and tracheoesophageal compression: a single institution's 25-year experience. Ann Thorac Surg 2001;72:434-9.

9 McLaughlin RB, Wetmore RF, Tavill MA, et al. Vascular anomalies causing symptomatic tracheobronchial compression. Laryngoscope 1999; 109:312-19.

10 Fearon B, Shortreed R. Tracheobronchial compression by congenital cardiovascular anomalies in children: syndrome of apnea. Ann Otol Rhinol Laryngol 1963;72:949-69.

11 Holinger LD, Lusk RP, Green CG. Pediatric laryngology and bronchoesophagology. Philadelphia, PA: Lippincott-Raven, 1997

12 Swischuk LE. Anterior tracheal indentation in infancy and early childhood: normal or abnormal? Am J Radiol 1971;112:12-17.

13 Fletcher BD, Cohn RC. Tracheal compression and the innominate artery: MR evaluation in infants. Radiology 1989;170:103-7.

14 Backer CL, Ilbawi MN, Idriss FS, et al. Vascular anomalies causing tracheosophageal compresson. Review of experience in children. J Thoracic Cardiovasc Surg 1989:97:725-31.

15 McElhinney DB, Hoydu AK, Gaynor JW, et al. Patterns of right aortic arch and mirror-image branching of the brachiocephalic vessels without associated anomalies. Pediatr Cardiol $2001 ; 22: 285-91$.

16 Harty MP, Kramer SS, Fellows KE. Current concepts on imaging of thoracic vascular abnormalities. Curr Opin Pediatr 2000;12:194-202.

17 Dahnert W. Radiology review manual, 3rd edn. Baltimore, MD: Williams \& Wilkins, 1996.

18 Moes CAF, Izukawa T, Trusler GA. Innominate artery compression of the trachea. Arch Otolaryngol 1975;101:733-8.

19 VanSon JAM, Julsrud PR, Hagler DJ, et al. Surgical treatment of vascular rings: the Mayo clinic experience. Mayo Clin Proc 1993;68:1056-63.

20 Moes CAF, Mawson JB, MacDonald C, et al. Right aortic arch with retroesophageal left aberrant innominate artery. Pediatr Cardiol $1996: 17: 402-6$.

\section{bmjupdates+}

bmjupdates+ is a unique and free alerting service, designed to keep you up to date with the medical literature that is truly important to your practice.

bmjupdates+ will alert you to important new research and will provide you with the best new evidence concerning important advances in health care, tailored to your medical interests and time demands.

Where does the information come from?

bmjupdates+ applies an expert critical appraisal filter to over 100 top medical journals A panel of over 2000 physicians find the few 'must read' studies for each area of clinical interest

Sign up to receive your tailored email alerts, searching access and more...

www.bmjupdates.com 